\title{
Mimaride Minyatürlerin Belge Niteliğinde Kullanımı Üzerine*
}

\author{
Ayşe ÇETiN **
}

özet

Kitap sanatları içinde metni betimleyen çalışmalar olarak görülen minyatürler, genel olarak bir metne bağlı, saray ve çevresi için tasarlanmış kitap resimleridir. Saray Nakkaşhanesinde çalışılan minyatürler klasik üslup dışında özgün, yaratıcı tasarımlar olarak da üretilmişlerdir. Sanatsal değerlerinin yanı sıra mimaride ve birçok farklı disiplinde belge niteliği özelliği de taşıyan minyatürler, restorasyonlarda olduğu kadar sürdürülebilir mimari çalışmalarında da önemli belgelerdir. Minyatürlerin, belge niteliklerinin öne çıkacak şekilde kullanılmamasının nedeni bu konuda çalışacak yeterli sayıda uzmanın bulunmamasıdır.

Dünya üzerinde projelerin belge kabullerinde fotoğraf, pul vb. sanat eserleri resmi belge niteliği taşıdığı kabul edilerek kullanıldığı halde, minyatürler aynı özelliği taşıyan belgeler olarak kabul görmemektedir. Türkiye sınırları içinde, koruma altına alınmış yapıların tescil belgelerinde hiç minyatür örneği kullanılmamış olması, restorasyon belgesi olarak mimari restorasyon projelerinde yer almamış olması bu konuda eksikliği sergilemektedir. Makalede minyatürlerin mimari belge olarak önemi ve nasıl çözümlenmesi gerektiği konusunda öneriler getirilmiştir.

Anahtar Sözcülkler: Minyatür, Mimari, Restorasyon, Restitüsyon, Geleneksel Sanatlar.

\section{The Utility of Miniatures as Documents of Architecture}

\section{Abstract}

Miniatures, which are forms of visual art, are drawings that generally describe the text in books that are written for the palace and its circles. Miniature products manufactured in royal Nakkaşhane are not limited to the classical style. Original, creative designs are also widespread. In addition to their value as works of art, miniatures are also significant since they architecture carry the quality of being documents for architecture and many other disciplines, and they can be used in restorations as well as sustainable architectural works. Miniatures' values as historical documents are not widely recognized since there aren't enough experts in this field.

Although art works such as photographs, stamps etc. are accepted as documents while accepting research project applications all over the world; miniatures are not accepted as documents of similar importance. This situation is evident in that no miniatures were mentioned in the registration certificates of listed buildings or in restoration documents of architectural restoration projects in Turkey. This study underlines the importance of miniatures as architectural documents and makes some suggestions for the solution of this problem.

Keywords: Miniature, architectural, Restoration, Restitution, Tradational Art. 


\section{Giriş}

Kitap sanatları içinde değerlendirilen minyatür, genel olarak bir metne bağlı, saray ve çevresi için tasarlanmış kitap resimleridir. Günümüzde sanat eseri olma değerlerinin dışında başta mimari olmak üzere birçok farklı disiplinde belge niteliği ile de ayrı bir önem kazanmıştır.

Mimaride, şehir planlamalarında, sürdürülebilir mimari planlarında, restorasyon çalışmaları ile restorasyona yönelik araştırma ve analizlerde, belge niteliği taşıyan minyatürler, bu konularda çalışacak uzman araştırmacıların azlığı ve etkili olamamaları nedeni ile belge nitelikleri öne çıkacak şekilde kullanılmamaktadır. Minyatürlerin içinde yer aldıkları metinlerde tasvir edilen mekânlar mimari detaylar çalışılan konuya göre biçimlendirilmiş olmaları nedeniyle doğal olarak, bir kısmı gerçekte var olmayan, hayali kurgulardır.

Osmanlı döneminde 16. yüzyılın ikinci yarısından itibaren üretilmeye başlanan tarih konulu minyatürlü yazmaların yanında yine aynı dönemin nakkaşlarından olan Matrakçı Nasuh'un şehirleri konu alan ve kompozisyonlarında, dönemin gerçek mimari ve bitki örtüsünü tasvir ettiği minyatürleri de bugünün mimarları için başlı başına birer görsel kaynaktır. Ancak, mimarlar tarafından minyatürlerin belge niteliğinde kullanılması için araştırmacıların minyatürleri çözümlemeye yönelik uzmanlık bilgisine sahip olmaları gereklidir. Uluslararası proje kabullerinde fotoğraf, pul vb. sanat eserlerinin resmi belge niteliği taşımalarından dolayı kullanılmalarının yanında, bu tür projelerde minyatürlerin de mimari için belge olarak kabul edilmeleri yerinde olacaktır. Bu konuda öncelikle minyatürlerin, mimari restorasyon ve analiz çalışmalarında birer belge olduğuna ilişkin bilincin geliştirilmesi, bu yönde bir farkındalığın oluşturulması gereklidir. Bu makalede, Osmanlı minyatürlerinin mimaride belge olarak kullanılmasının önemi ve gerekliliği üzerinde durularak minyatürlerdeki unsurların mimari açıdan nasıl çözümlenebileceği üzerine öneriler getirilmiştir.

\section{Minyatür Çözümlemede Yapı-Mekân Tanım ve Analizleri}

Minyatür dilinin anlaşılabilmesi için yapılması önerilen çözümleme çalışmasına örnek olarak, Matrakçı Nasuh'a ait, “Beyan- Menazil- Sefer-i Irakeyn” adlı eserde yer alan minyatürler seçilmiştir. Eserde yerleşim ve yapı grupları ile yapılarda yer alan mekânların tanımlanması, canlı ve cansız detay betimlemelerinin değerlendirilmesi ile mimari kompozisyon düzenle- ri, türleri, çizim programları ve çalışma tekniklerinin farklı açılardan incelenmesi, yöntem olarak önerilmektedir.

\section{Alan, Mekân}

Mekânlar irdelendiğinde Matrakçı Minyatürleri'nin tasarımlarında daima rasyonel bir mantık sürdürüldüğü gözlemlenmektedir. Bu minyatürlerde genel olarak adeta bir seyir belgeleme defteri mantığı ile detaylı olarak not alınmış ve betimlenmiş gibi görülen bir teknik ile yapılar şablonsuz resmedilmiş, kentin mimari ölçü ve biçimi belge niteliğinde çalışılmıştır. Sistemli çalışılmış olan yapıların katları, detayları, malzemeleri kent planı içinde incelendiğinde çoğunun günümüzdeki konumları ile örtüştüğü görülmektedir. Kentin ulaşım sirkülâsyonu dahi minyatürlerde hiç insan olmamasına rağmen ölçekli olarak açıkça algılanabilmektedir.

Çağdaş planlama çalışmalarının bir kısmında, günümüzde dahi bulunmayan bu sistematik açık fonksiyon şemalı plan tasvirleri bize sanatçının, yapıları salt görsel hacimler olarak algılamasından çok daha derin bir mimari bilgi donanımına sahip olduğunu da göstermektedir. Kentlerin konum planları, birbirleri ile ilişkileri, bağlantı kapıları, köprü ve yol gibi ulaşım bağlantıları minyatürlerinde görsel destekler ile güçlendirilerek görüntülenmiştir.

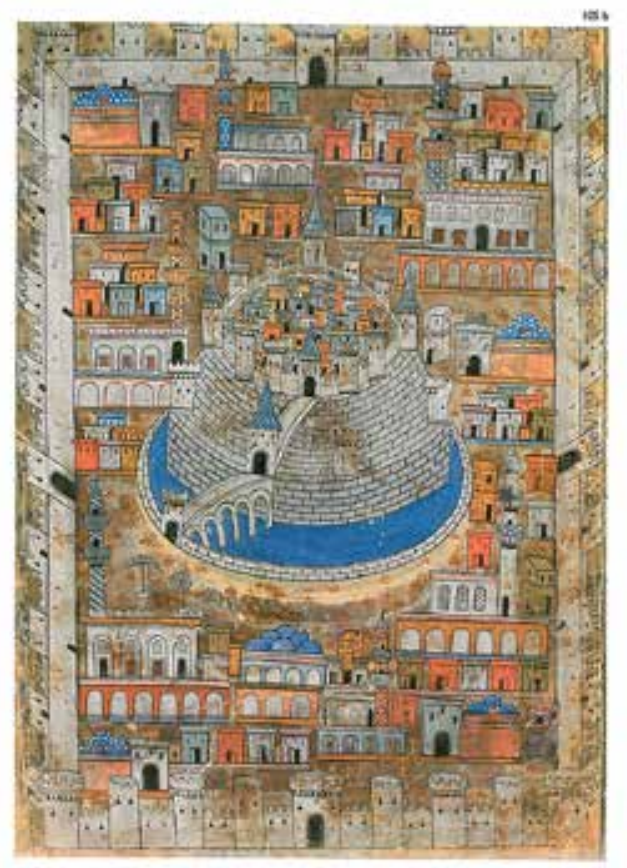

Resim 1. Matrakçı Nasuh, Beyan- Menazil- Sefer-i Irakeyn, “105. Varak b Yüzü Kağıt üzerine fırça çalışması” (16.yy. İstanbul üniversite Kütüphanesi, İstanbul, Atasoy, 2015) 
Atasoy, Beyan-I Menazil- Sefer-İ Irakeyn Minyatürlerini şöyle açıklamaktadır:

“Nasuh'un önemli olanı öne çeken tavrı İstanbul tasvirinin genel görünümünde de görülür. Sanatçı şehrin en önemli yapılarını ve özelliklerini ele almış ve bunların aralarındaki evleri de temsilcileri ile göstermeyi tercih etmiştir. Bütün camiler, kiliseler, Bizans ve Osmanlı yapıları, anıtlar, kıyı şeritlerindeki özellikler, limanlar en can alıcı özellikleriyle canlandırılmışlardır. "(Atasoy, 2015,10).

İstanbul sahnelerinin çalışıldığı Toplam 7 adet, albümden seçilen "Galata betimlemesi” minyatürü incelendiğinde şaşırtıcı şekilde günümüz kent silueti ile örtüşen tarihi doku silueti de görülmektedir. Matrakçı'nın Galata Minyatürü'nde yer alan tarihi yapıların birçoğu günümüzde de aynı yerlerde bulunmaktadır. Bu güne ulaşamamış olan yapıların ise yıkılmış olabileceği düşünülmektedir. Klasik minyatürlerde görülen, sanatçının kurgusu olan yerleştirmeler ise Matrakçı'nın minyatürlerinde görülmemektedir. Genel olarak minyatürlerde görülen sanatçının tasarladığı ve aslında olmayan mekânlar, konuya adaptasyonu için olayların başka bir mekânda gösterilmesi gibi çalışmalar, Matrakçı'nın 'Beyan-ı Menazil- Sefer-i Irakeyn' adlı eserindeki minyatürlerde yer almamaktadır.

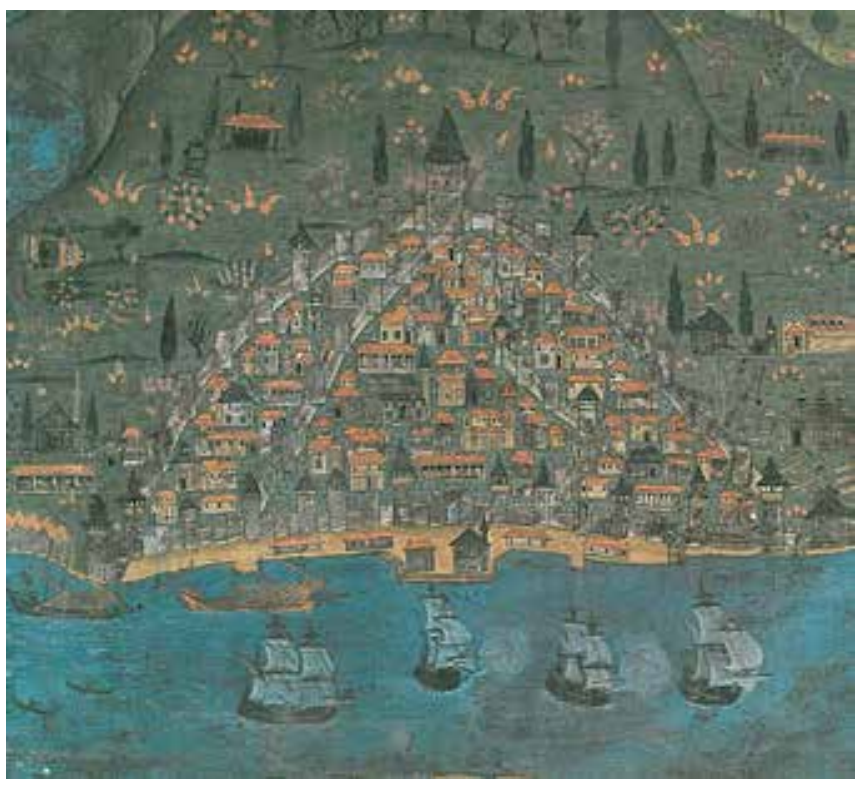

Resim 2. Matrakçı Nasuh, Beyan- Menazil- Sefer-i Irakeyn, "9. Varak a yüzü Galata Kağıt üzerine fırça çalışması” (16.yy. İstanbul Üniversite Kütüphanesi, İstanbul Atasoy, 2015)
Matrakçı'ya ait minyatürler genel olarak kitap içinde farklı boyutlarda yer aldığı sayfa düzenleri ile uyumlu, değişik ölçülerde çalışılmıştır. Minyatürlerde sıkça görülen geometrik tekrarlı zemin deseni uygulamaları yapılmamış, arazi canlandırmaları, kent veya bina tasarımları yüzey görünümleri ile aynı renk ve ölçüde resmedilmiştir. Menazilname Minyatürleri'nin iç ve dış mekân kompozisyonlarında doğadan topoğrafik detaylar, bitki ve hayvan betimlemeleri orijinal boyut ve görselleri ile detaylı olarak yer almaktadır. (Resim 2)

Gerçek konum ile kurgulanmış olan Menazil Minyatürleri'nin kompozisyonlarında, bitki ve hayvan detayları, aynı zamanda bir doğa albümü şeklinde alan ile örtüşen belgeleme çalışmalarıdır. Bu uygulama yöntemi ile belgelenmiş olan yerleşim alanlarında öncelikle çadırlar, kaleler, köprüler, anıt yapılar ve dini yapılar çalışılmıştır. Küçük kentlerde, sur dışında konuşlandırılan çadırların konumlandırılmalarında ayrıca oranlar gözetilerek, ölçekli olarak irdelendikleri sonucuna da ulaşmak mümkündür. (Resim 3)

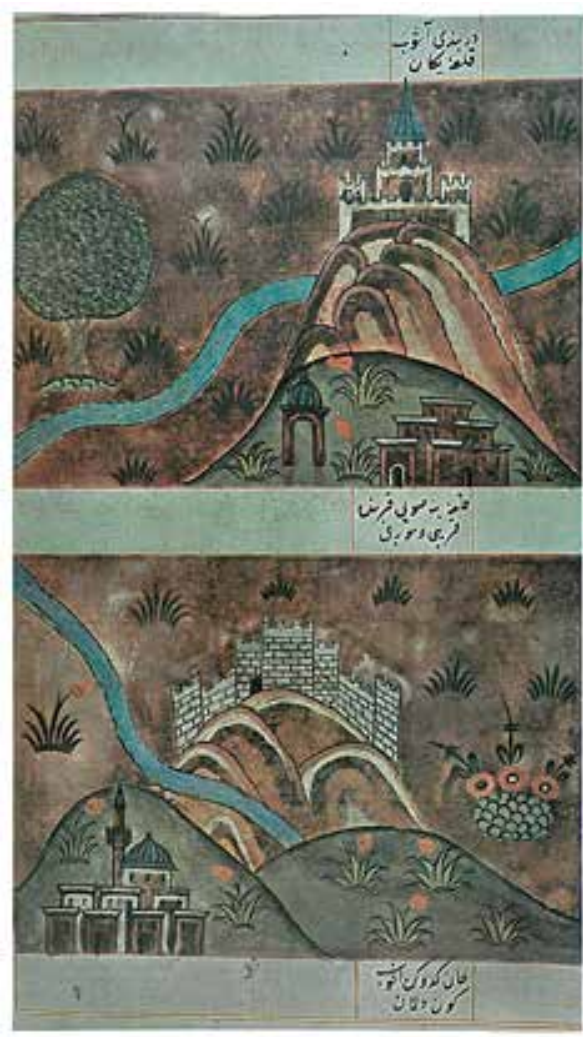

Resim 3. Matrakçı Nasuh, Beyan- Menazil- Sefer-i Irakeyn, 87. Varak b yüzü, Kağıt üzerine fırça çalışması (16.yy. İstanbul üniversite Kütüphanesi, İstanbul Atasoy 2015 ) 


\section{Doku-Malzeme-Bezeme}

Eserde bulunan bütün minyatürlerin, yapılarda var olan, yapı kaplama malzemelerini ifade eden, doku detayları incelendiğinde, mekân çalışmalarında, en çok malzeme yorumlanan alanların, iç ve dış duvarlar olduğunu görülmektedir. Renkli taş detayların çalışıldığı eserde; bazı bölgelerdeki yapıların farklı renk ve dokular ile betimlenmesi, sanatçının tasarrufu olmayıp, dönem mimarisinde oldukça farklı yapı malzemelerinin kullanılmış olmasından kaynaklanmaktadır. Yer kabuğunun, doğudan batıya değişen malzeme ve renginin, sanatçıların eserlerinde de farklılaşarak yansıması bu nedenledir. Bu sadece duvar örgülerinde olmayıp ağırlıklı olarak çatılarda olmak üzere, yapıların farklı mekânlarında da görülmektedir. Çatılar incelendiğinde kiremit dokularındaki farklılıkların geleneksel üretim çeşitliliğinden kaynaklandığı, günümüzde de halen süren bir uygulama olmasından açıkça görülmektedir. Kullanılan pişmiş toprak yapı malzemelerinin, minyatürlerde aynı görüntüde olmaması, yerel kiremit üretimlerinde bölgesel olarak değişen farklı teknik, model ve ölçülerin kullanılmasından kaynaklanmaktadır. Eser genelinde görülen farklı çatı dokuları bu nedenle belge niteliğindedir ve bölgelerin geleneksel yapı malzemelerinin farklı dönemlerde üretimlerini yansıtmaktadır.

Farklı çatı kaplama tekniklerinin bölge iklimi ile ilişkisini yansıtan bazı çalışmalar, sanatçı yorumu gibi görünmektedir. Örneğin halen uzun süreli kar altında kalan bölgelerde yapılan metal kaplama uygulamaları ve dikliği ile farklılık gösteren çatı dokularını, bazı sanatçılar minyatürlerinde gümüş varak kullanarak belgelemiştir. Günümüz makalelerinde dahi minyatürler yorumlanırken, farklı bezemeler gibi 'gümüş yaldızla boyalıdır' diye sanatçıya atfedilen bu yüzeyler, minyatür tekniği ile yorumlanmış yapı detay tanımlamaları olarak görülmemektedir. Çevre etkenleri sonucu ortaya çıkan, görünümleri aktaran bu çalışmalar, aslında minyatürlerin sürdürülebilir mimari ve restorasyonlarında belge oluşturması bakımından önemlidir.

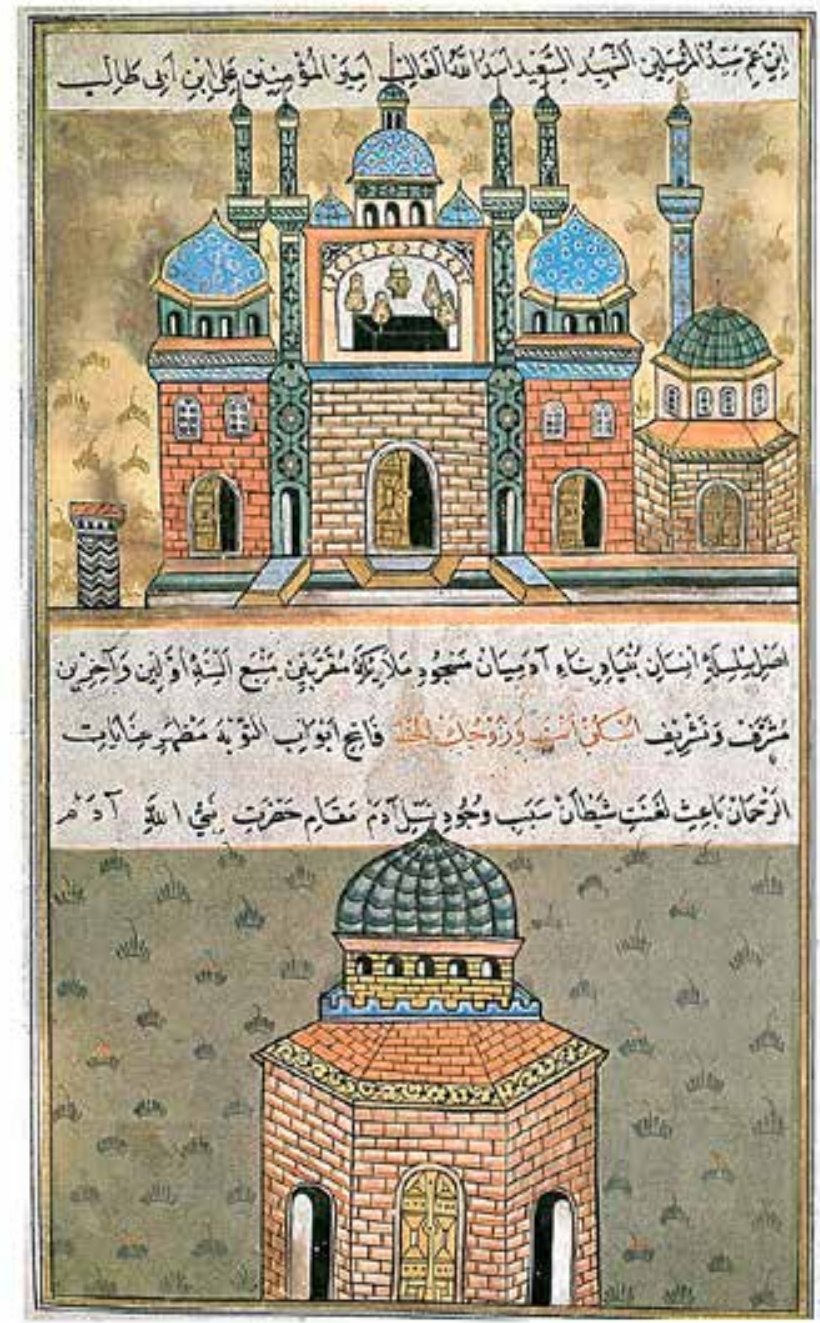

Resim 7. Matrakçı Nasuh, Beyan- Menazil-Sefer-i Irakeyn, 58. Varak b Yüzü, Kağıt üzerine fırça çalışması (16.yy. İstanbul Üniversite Kütüphanesi, İstanbul Atasoy 2015)

Doku ve malzeme detayları yapıların kapı, pencere tavan, taban ve mobilyalarının ince yapı detaylarında da görülmektedir. Ahşap ve lake üzerine farklı desenli nakışlar ile renklendirilerek çalışılmış olan bitki ve hayvan detaylı motifler de oldukça gerçekçi olarak çalışılmıştır. Minyatürlerde yer alan bazıları altın kaplamalı ve mücevherli dahi olan, tahtlardan çadırlara, halılardan kumaş desenlerine kadar farklı doku, renk ve desenlerde çalışılmış olan figürler mimaride malzeme ve doku çeşitliliğini de detaylı olarak tanımlamaktadır. Günay, 1992, Süleymanname Minyatürleri'nde Mekân Ve Anlatım Teknikleri başlıklı makalesinde bu konuda "Minyatürde mimari yüzey dolgusu olarak görülen desenler, şüphesiz ilk dönemlerde mimari üzerinde de kullanılan bezemelerin bir kopya- 
sıydı ve bu bezemeler mimariyle birlikte diğer el sanatlarında da uygulanıyordu. Bu mimari bezemeler Horasan, Özbekistan ve İran'daki yapılarda panolar ve şeritler halinde tuğla, çini, mozaik çini ve stuko olarak iç ve dış cepleri kaplıyordu. Gerçekten o yörelerdeki bezemelerin desenleri ve mimari içinde yer alışları, minyatürdekilere çok benzemektedir”, bilgilerini aktarmaktadır.

“15. yüzyıldan itibaren görülen ve bireysel bir üretim biçimi olarak tanımlayabileceğimiz çizgisel, renkli tek sayfa minyatürler, İslam tasvir geleneği içinde, biçim ve uygulama teknikleri bakımından farklı bir yer edinmiştir. Bu üslûbun temsilcilerinin siyah ve renkli mürekkeple veya suluboya tekniğinde uyguladığı minyatürlerde, fırçayı farklı ton değerlerinde kullanarak tasvir ettiği herhangi bir biçimi salt çizgi ile ifade etmiştir. Formu belirgin hale getirmeye ve hareketi ifade etmeye yarayan bu fırça tekniğinin, renklendirme aşamasından önce kalemle yapılan, desenin dış hatlarını gösteren ve eskiz çizimine ihtiyaç duyulmadan uygulanan bir teknik olması muhtemeldir. Bu teknikte, figürün dış hatları çizilerek, kompozisyona yerleştirilecek elemanlar belirginleştirilmiş ve sonrasında formu ortaya çıkaran nüanslı çizgiler, serbest bir şekilde tek bir fırça hareketiyle uygulanmıştır. Ustalıkla uygulanan bu çizgisel üslûp, Batı resim geleneğindeki gibi, yanılsama yaratmak üzerine kurulu bir perspektif anlayışına sahip olmayan ve görüneni tasvir etmeyi amaçlamayan İslâm tasvir geleneğindeki anlayıştan ayrı düşmüştür. İslâm tasvir geleneğinde nesnenin taklit edilmesi amaçlanmaz, ancak, o nesneyi hatırlatan, temsil eden bir biçim oluşturulur. Bu biçim, geçmişte üretilmiş olan benzer biçimlerin yeniden üretimidir ve o nesneye ilişkin herhangi bir öznel nitelik atfetmez. Bu noktada eserlerinde öne çıkan bu çizgisel üslûp, İslâm tasvir geleneğinde, ânı tasvir etmenin ve figürün bireyselliğini ifade etmenin yolunu açmıştır.” (Adıgüzel Toprak, 2015:109-121).

\section{Minyatürlerin Çalışılma Teknikleri, Çizim Programları}

Minyatür çalışma teknikleri konunun uzmanları ve araştırmacılar tarafından "Minyatürlerin bilinen, genel çalışılma düzeninde; hattatlar, metni yazmakta ve minyatürün yer alacağı sayfaya geldiğinde buraya girecek beyitleri yazarak varakları nakkaşlara vermektedir." ve "Nakkaşlar bu yazıların yerlerini de düşünerek kompozisyonlarını yapmakta ve yazıları kutular içine almaktadır. Nakkaşlar kompozisyonu tasarlarken gerekli görürse çerçevede değişiklikler de yapmaktadır. Kompozisyonlar, konuya göre kişilere, duracakları yerlere ve mekâna önem verilerek hazırlanmakta, daha sonra zeminleri boyanıp ve bezenerek, figürleri ve doğa ayrıntıları yapılmaktadır. En son olarak da cetvelkeşler cetvelle düz konturları ve çerçeve çizgilerini çekmektedirler”. (Günay,1992:66) olarak tanımlanmaktadır.

Minyatür çizim programları incelendiğinde ise yapı cephelerinin art arda kaydırılarak, aksonometrik perspektifte iki düzlemde tasarlandığı, üçüncü boyut olan derinliğin ise çalışılmadığı görülmektedir. Bazı minyatürlerde üçüncü boyut ve derinlik duygusunun oluşması ise kuşbakışı görünümde, yapı üstlerinin, derinliği ile birlikte görülebilecek şekilde çalışılmış olmasından kaynaklanmaktadır. Adıgüzel Toprak (2015) makalesinde ise çizgi ve minyatür sanatının ilişkisi şu şekilde yorumlanmaktadır;

“Çizgi, teknik bir tanımla, iki nokta arasındaki en kısa iz olarak anlatılsa da, sanatta çizgiyi hareketin sürekli izi olarak tanımlamak gerekir. Hareket halindeki çizgi, dinamik ve izleyicinin göz hareketiyle takip etmesi gereken bir eylem yaratır. Böylece çizgi, tek başına veya diğer tasarım unsurlarıyla birlikte, renkli veya tek renkli kompozisyonlarda kullanıldığında, izleyicinin gözünü vurgulanmak istenen odağa yönelten bir güce sahiptir. Çizgiler aracılığıyla göz, imgenin formunu ve sınırlarını (dış hatlarını) algılar; böylece, tasvir edilmiş olan şeyin biçimi, niteliği, kompozisyon içindeki yeri ve diğer unsurlarla olan ilişkisi zihinde canlanır. Çizgiyle başlayan tasarlama sürecinde, formun/formların ortaya çıkmasıyla kompozisyon oluşur. İslâmiyet ile birlikte gelişen yazmaların içinde yer alan minyatürlerdeki kompozisyon anlayışı ise, tarihî bağlamda üslûplara ve konuya göre farklılıklar gösterse de, tasarımın evrensel ilkelerini kapsamış ve kullanmıştır. Bir tasarımda kullanılan tek başına düz bir çizgi en soyut elemanlardan biridir" (Pipes, 2003, :20). Buna karşılık tek bir çizgi boyutu ve hareketi (yönü) ile her türlü şekli ve duyguyu izleyiciye geçirebilir, tek bir çizgi ile form biçimlenebilir. Bu noktada kökenleri İslâmiyet öncesinde Uygurlara kadar giden duvar resimleri ve dokumalarda, İslâmiyet sonrasında ise minyatürlerde kendini gösteren tasvir geleneğinde çizginin önemli bir yeri olduğu söylenebilir. Batı resim geleneğinin temelini oluşturan mimetik (öykünmeci), do 
ğayı ve görünen gerçekliği taklit eden sanat anlayışının aksine, bilginin aktarıldığı ve bilinenin görünür kılındığı bir tasvir anlayışında çizginin önemli yer tutması kaçınılmazdır. Nüanslı çizgi, formu taklit etmeyi amaçlamaz; ancak, formun dış hatlarını sınırlandırıyor gibi görünse de, aslında, formu görünür hale getiren temel unsurdur. Bir kompozisyonda, çizginin formu tanımlamaya yarayan bir işlevi olmasından dolayı, çizgi, renkten de önce gelir. Çizgi, formu gösterirken boşluğu tanımlayan bir etki yarattığı için, renk kullanılmadan da form ifade edilebilir. $\mathrm{Bu}$ açıdan bakıldığında kitap sanatlarında formu ifade etme özelliğiyle, salt çizginin ve farklı ton değerlerinin kullanıldığı kompozisyonlar dikkati çeker”. (Adıgüzel Toprak, 2015`:127)

\section{Önerilen Yöntem ve Sonuç:}

Günümüz mimarisi ile karşılaştırmalı olarak incelenen minyatürlerde belge niteliğinin tespiti için, içinde mimari eserler yer alan minyatür örneklerinin incelenmesi, belge özelliklerinin ortaya çıkarılması gerekmektedir. Minyatürlerin belge özelliği, hatalı algılar nedeni ile uzun yıllar boyunca anlaşılamamıştır. Bu da minyatürlerin genel olarak hayali kurgular ve detaylar içermesi ve çoğunlukla da belge niteliği taşıyabilecek gerçek dışı tasvirler olarak algılanmasından kaynaklanmaktadır. Yaşam şekilleri, dönem anlayışı gibi kavramların da incelendiği minyatürlerde görülen kent konum tasarımları ve yapılar incelenirken, bu mekânların gerçek mekânlarla ilgisi, ölçü ve görselliklerinde ne kadar gerçeğe yakın kalındığını irdeleyen analizler yapılmalıdır.

Mimari sürdürülebilirliğin izini sürmek adına yapılabilecek araştırmaların; günümüz yerleşim planları ve yapı verilerinin minyatürlerdeki karşılıkları ile detaylı olarak incelenmesi, analiz ve sonuçlarının detaylı olarak irdelenmesi çok önemlidir. Bu çalışma sistematiğiyle projeler ile minyatürlerin eş zamanlı ve detaylı bakış tekniği ile incelenebilmesi için genel minyatür bilgilerinin yanı sıra, sanatçı ve eser de tanınmalıdır. Minyatürü anlamak ve belge niteliğinde değerlendirebilmek için bu bir gerekliliktir.

Farklı disiplinlerin işbirliği ile farklı yüzyıllarda üretilmiş olan eserlerin dahi belgeleme ve analizlerinin yapılması gerekmektedir. Yakın yüzyıllar arasında üretilmiş veya çok daha eski belgeler olmalarına rağmen, günümüzde olay mekân çözümleme çalışmalarında bu eserlerden, aynı zamanda, yarar- lanılması mümkündür. 'Evliya Çelebi’nin seyahatnamesinde anlattığı yerlerin, Matrakçının Menazilnamesi gibi birçok minyatürde çalışılmış olan görseller ile örtüşmesinin, karşılaştırmalı kontrolü’ çalışma örneğinden görüldüğü gibi ‘Eserlerin Belge Özelliğinden' yararlanırken bir nevi kontrolünün yapılması da mümkündür. Sağlama olarak görülen bu gibi çalışmalarda yazılı eserlerin görsel eserler ile karşılaştırılmasının sanatçı ve yazarlar tarafından çözümlenmesi gereklidir. Sıkça kullanılan bu belge karşılaştırma yöntemi, yazarın gitmiş ve anlatmış olduğu yerlerin minyatürlerdeki betimlemeleri ile karşılaştırılarak yeni belgelerin oluşturulmasıdır.

Gerçek Olay Mekân Belgeleme araştırma çalışmalarında günümüzde de var olan, varlığını sürdürebilen yapıların yer aldığı minyatürlerin seçilmesi daha kolay bir yöntemdir. Mutlaka gerekli değildir, restitüsyon projelerinden yararlanılması da mümkündür. Minyatürlerde yer alan yapıların ve kent planlarının sürdürülebilirliği; işlevlerinin, konstrüktif yapı özelliklerinin devam ediyor olması, konum olarak korunmuş olmaları ve kent planına etkilerinin belgelenmesi karşılaştırmalı analizlerde öncelikli çalışmalardır. Karşılaştırmalı analizlerde;

- Minyatürlerde yer alan, günümüzde de var olan yapılar üzerinden oran, malzeme, strüktür gibi tespitler ile betimlemenin gerçekliğinin araştırılmasının mümkün olması,

- Minyatürlerde yer alan yapıların günümüze ulaşmış olanların yapım hedeflerine yakın kullanımları ile işlevlerinin sürdürülebilirliğinin devam ediyor olması, (Bu aynı zamanda tarihi yapıların tasarımlarında ve kent içi kullanımlarında planlama süreçlerinde işlevlerinin ne kadar başarılı olarak seçilmiş olduğunu da göstermektedir.) Analiz çalışma plan hedefinde olmamasına rağmen elde edilen sonuçların restorasyon projeleri kadar sürdürülebilir mimari açısından da belge değeri taşıyor olması,

- İncelenen alanda, Minyatürde ve günümüzde genel yapı detay tipolojilerinin tablo çarpanlarının verileri, değişen kent yaşamının planlama verilerini de içermektedir. Belgelemenin kent plancıları açısından yeni bir veri tabanı oluşturması, (Karşılıklı olarak iki farklı minyatür alanının günümüz görüntüleri ile karşılaştırılması dahi, bölgesel, zamansal farklılık analizlerine veri oluşturabilmektedir.)

- Ayakta kalan yapılar ve sayısal karşılaştırma oranları ile aynılık oranı sayısal verilerine de ulaşmanın mümkün 
olması, bunun da mimaride sayısal belge çıktısı olarak kullanılabileceği anlamına gelmesi, ortaya çıkan sonuçların mimaride, kent planlarında, sürdürülebilir mimari, restorasyon çalışmalarına yönelik araştırma ve analizlerde, belge niteliği taşımaktan ileri yönlendirici olabilme özelliklerinin araştırılması ile mümkündür.

- Minyatür tekniğindeki canlı cansız biçimlerin betimlenmesinden yola çıkılarak bina, alan gibi mimari detayların, günümüz medya verileri ile karşılaştırılması sonucu ortaya çıkan analizlerde minyatürlerde çizginin kullanımı ve kurgularının gerçekçiliği üzerinden gerçek olay mekân belgeleme akımı d ayrıca belgelemektedir. Günümüz medya verileri ile minyatürlerde betimlenmiş olan mimari detayların karşılaştırılarak analizleri yapıldığında ortaya çıkan bilgi ve görseller, minyatürlerin belge niteliğinin de farkındalığını oluşturmaktadır.

- Belge niteliği taşıdığı kabul edilen fotoğraf, pul gibi eserler ile birlikte minyatürlerin de belge niteliği taşıyan eserler olarak anılması ve çalışılması mümkündür. Belge niteliği taşıyan minyatürlerin, bu özelliklerinin ortaya çıkarılması, belge niteliklerinin vurgulanarak bilinirliğinin arttırılması gereklidir.

\section{KAYNAKÇA}

Adıgüzel Toprak, F. (2007). Arifi'nin Süleymannmesi'ndeki Minyatürlerde Saltanata İlişkin Simgeler. İzmir: Dokuz Eylül Üniversitesi Güzel Sanatlar Enstitüsü Yayınları. (Yayınlanmış Sanatta Yeterlik tezi)

Adıgüzel Toprak, F. (2015). “Minyatürde ‘Çizgi’, Rızâ-yi Abbâsî’nin Tek Sayfa Minyatürleri”. Art-Sanat 3, 109-121.

Atasoy, N. (2015). Beyan-I Menazil-Sefer-İ Irakeyn Matrakçı Nasuh IIstanbul: Masa Yayınları

Ayvazoğlu, B. (1989). İslâm Estetiği ve İnsan, İstanbul: Çağ Yayınları.

Dinçer, K. (1994) İzmir ve Ege’den Mimari İzlenimler. İtalya, AmilcarePizzi SpA

Günay, R. (1992). "Süleymanname Minyatürlerinde Mekân ve Anlatım Teknikleri”. Topkapı Sarayı Müzesi Yıllık 5, 56-159

Nasuh, M. (16.YY.). Beyan-I Menazil- Sefer-İ Irakeyn. İstanbul: İstanbul Üniversitesi Kütüphane ve Dokümantasyon Daire Başkanlığı Nadir Eserler Kütüphanesi.

Pakalın, M.Z. (1993). Osmanlı Tarih Deyimleri ve Terimleri Sözlüğü III. İstanbul: Milli Eğitim Bakanlığı Yayınları.

Pipes, A. (2003). Foundations of Art and Design, Londra: Laurence King Publishing.
Renda, G. (1977). Batılılaşma Döneminde Türk Resim Sanatı. Ankara: Hacettepe Üniversitesi Yayınları.

Yurdaydın, H.G. (1976). Nasuhü's-Silahı (Matrakçı)'Nın Beyan-I Menazil-İ Sefer-İ Irakeyn-İ Sultan Süleyman Han. Ankara: Türk Tarih Kurumu Basım Evi. 